\title{
Insight into secondary metabolites of Stachybotrys, Memnoniella, Doratomyces and Graphium between benefits and harmful
}

\author{
Waill A. Elkhateeb ${ }^{1 *}$, Ghoson M. Daba ${ }^{1}$ \\ ${ }^{1}$ Chemistry of Natural and Microbial Products Department, National Research Centre, Dokki, Giza, 12622, Egypt.
}

'Corresponding Author: Waill A. Elkhateeb, Chemistry of Natural and Microbial Products Department, National Research Centre, Dokki, Giza, 12622, Egypt.

*Corresponding Author: Bon L.I., Candidate of Biological Science, associate professor of Chair of pathological physiology of the name of D.A. Maslakov, Education Establishment "Grodno State Medical University".

\section{Received date: November 17, 2021; Accepted date: December 15, 2021; Published date: January 05, 2022}

Citation: Waill A. Elkhateeb, Ghoson M. Daba (2022) Insight into secondary metabolites of Stachybotrys, Memnoniella, Doratomyces and Graphium between benefits and harmful. J, Biotechnology and Bioprocessing 3(1); DOI: 10.31579/2766-2314/066

Copyright: (C) 2022, Waill A. Elkhateeb, This is an open access article distributed under the Creative Commons Attribution License, which permits unrestricted use, distribution, and reproduction in any medium, provided the original work is properly cited.

\section{Abstract \\ Stachybotrys, Memnoniella, Doratomyces and Graphium all these genera belonging to Class: Sordariomycetes. This review is to demonstrate description, ecology, and secondary metabolites from Stachybotrys, Memnoniella, Doratomyces and Graphium and some of their reported biological activities. Besides, describing the importance and potentials of those fungi in order to encourage for further studies to each genus metabolites and purify already known metabolites. \\ Keyword: stachybotrys; memnoniella; doratomyces; graphium; secondary metabolites; biological activities}

\section{Introduction}

Drug discovery has focused on microbial sources where nearly $80 \%$ of the world's antibiotics have their origins. These sources have almost entirely been from soils collected from around the world, but new microbial habitats need to be examined for microbiota that produces useful bioactive compounds. Fungi and other microorganisms represent an invaluable source of natural product bioactive compounds, which are exploited in various contexts, ranging from crop protection to human medicine [1]. Fungi in general and endophytic fungi especially are excellent sources of novel, bioactive natural products. Although the antimicrobial bioactivities are the most easily assayed and other activities include anticancer, insecticidal, antiviral, anthelmintic, anti-plasmodial and immunomodulatory [2].

Schueffler and Anke, [3], reported that "between 2009 to 2013" approximately 100, 000 fungal species are known and more than one million are expected. The variety of species allow that fungi continue to be a rich source of new metabolites. Besides the traditional fungal isolates, an increasing interest in endophytic and in marine-derived fungi has been notice. Terrestrial fungi have produced many therapeutically significant molecules. However, the potential of marine fungi has only been investigated to a limited extent. In addition new screening strategies based on innovative chemical, biological, and genetic approaches have led to novel fungal metabolites in recent years. [3]. Several fungi engage in pharmaceutical industry, enzymes, food, and some take part in biotechnology, while some are sources of natural products with diverse chemical entities and wide applications. Fungi are well known biotechnological tools that have various applications in the fields of industry. Thanks to their ability to produce set of prestigious enzymes that is eco-friendly and can replace harmful chemicals used in those industries. [4-15].

This review highlights on Class: Sordariomycetes genera (Stachybotrys, Memnoniella, Doratomyces and Graphium) secondary metabolites. Also, screen for, and discover novel metabolites produced by those potent fungi in order to be involved in additional applications. Moreover, describing the unique chemical diversity of these fungal genera involved in medical, pharmaceutical, agricultural applications. Also highlight the harmful side of these filamentous fungus if present.

\section{Stachybotrys, Memnoniella, Doratomyces, Graphium, description and ecology}

The genus Stachybotrys belong to Ascomycota division; Class: Sordariomycetes; Order: Hypocreales; Family: Stachybotryaceae. Colonies usually blackish, hyaline or brightly coloured in one species only; conidiophores erect or suberect, unbranched or branched, hyaline or dark-pigmented, smooth or roughened, sometimes covered in part with dark granules, with apical clusters of phialides; phialides elliptical, subclavate or broadly fusiform usually with a small opening; phialoconidia sliming down to form slimy glistening heads, one-called, dark pigmented or hyaline, smooth or rough, sometimes covered with 
dark granules, sometimes with longitudinal striations, elliptical, reniform, oval, subspherical or lemon-shaped (Figure, 1). The most common Stachybotrys species is Stachybotrys chartarum and Stachybotrys elegans. Stachybotrys chartarum; colonies slow-growing attaining $2.2 \mathrm{~cm}$ in diameter after 10 days on malt extract agar at 25C. Stachybotrys chartarum is worldwide and has been isolated from soil. Stachybotrys elegans; colonies attaining $4.5 \mathrm{~cm}$ in diameter after 7 days on malt extract agar at $25 \mathrm{C}$, Conidia hyaline and broadly fusiform elliptical, ovate or subglobose $[14,16]$.

The genus Memnoniella belong to Ascomycota division; Class: Sordariomycetes; Order: Hypocreales. Colonies dark coloured velutinous or powdery; conidiophores erect, unbranched or sometimes forked, dark coloured, smooth or minutely verruculose; conidiogenous cells phialidic, in groups of up to 10 at the tip of conidiophore, clavate, cylindrical or elliptical; conidia in long persistent chains, one-celled, dark colour, smooth or echinate. The most common species is Memnoniella echinate; colonies moderately growing, attaining $5 \mathrm{~cm}$ in diameter after 10 days on malt extract agar at $25 \mathrm{C}$, margin white changing to greyish towards the center (Figure, 2). Memnoniella echinate is very widely distributed common in soil and on cellulosic substrates and is known to be a good cellulose decomposer. Memnoniella is a related genus to Stachybotrys, but in the former, the phialoconidia do not slime down but are held together in long chains $[14,16]$.

The genus Doratomyces belong to Ascomycota division; Class: Sordariomycetes; Order: Microascales; Family: Microascaceae. Doratomyces is a genus of the fungi imperfecti, closely related to Scopulariopsis (Figure, 3). Colonies greyish to black, velvety, floccose or powdery; conidiophores aggregated to form erect synnemata, each with a sterile stalk and fertile head; head composed of a central axis of anastomosing hyphae branching towards outside and bearing conidiogenous cells at the ultimate branchlets; annellophores ampulliform or lageniform; conidia born in long chains, dark, i-celled, elliptical, ovate or subglobose, rounded or apiculate at the apex, truncate at the base, smooth or roughened. Doratomyces differs from Trichurus by the absence of sterile hairs interspersed with the fertile hyphae of synnematal head. Doratomyces widespread in agriculture soil and the most common species is Doratomyces stemonitis. Doratomyces stemonitis colonies slowgrowing attaining $1.8 \mathrm{~cm}$ in diameter on malte extract agar after 7 days at $25 \mathrm{C}$, margin whitish conidial areas dark grey, becoming black in age, surface synnematous; synnemata up to 1200 um high with globose to elongate or cylindrical fertile heads $[14,16]$.

The genus Graphium belong to Ascomycota division; Class: Sordariomycetes; Order: Microascales; Family: Microascaceae (Figure, 4). Graphium is a genus of the fungi imperfecti. Colonies dark coloured with erect synnemata, synnemata stout, darkly pigmented, each capped by a slimy head, individual element of each synnema diverging at the apex, branching penicillately; conidiogenous cells annelliform, born in verticils at the tips of branches, subulate or cylindrical; conidia (annelliconidia) cylindrical or widge-shaped, rounded at the apex, truncate at the base, hyaline or subhyaline, smooth, one-celled, produced in basipetal succession, but gathered in slimy heads. Graphium colonies attaining $4.5 \mathrm{~cm}$ in diameter after 7 days on oat meal agar at $25 \mathrm{C}$. Graphium was isolated from soil containing cellulosic materials [14, 16].
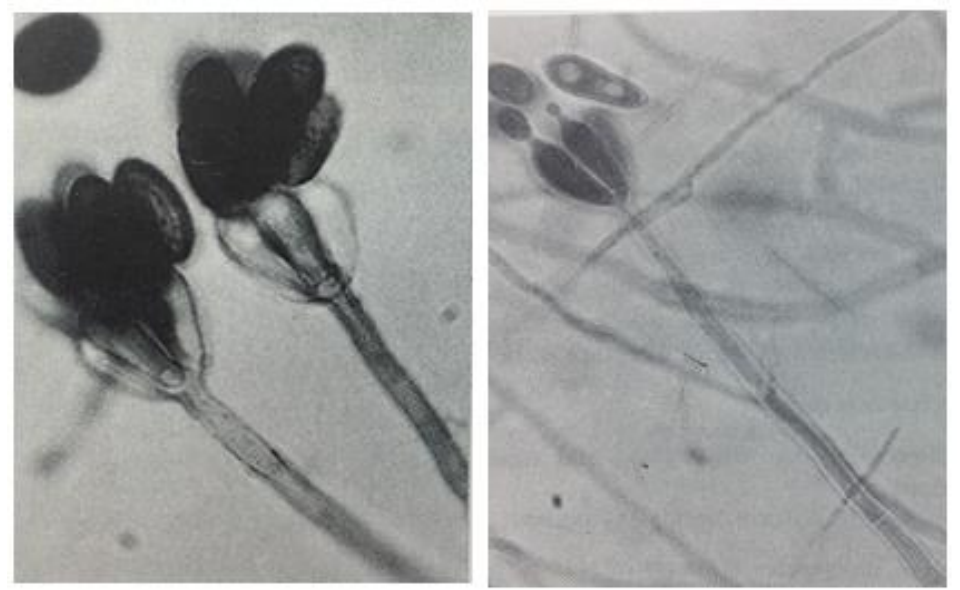

Figure (1). Stachybotrys spp., different species, Photo was taken by Dr. Moubasher AH. [16]. 


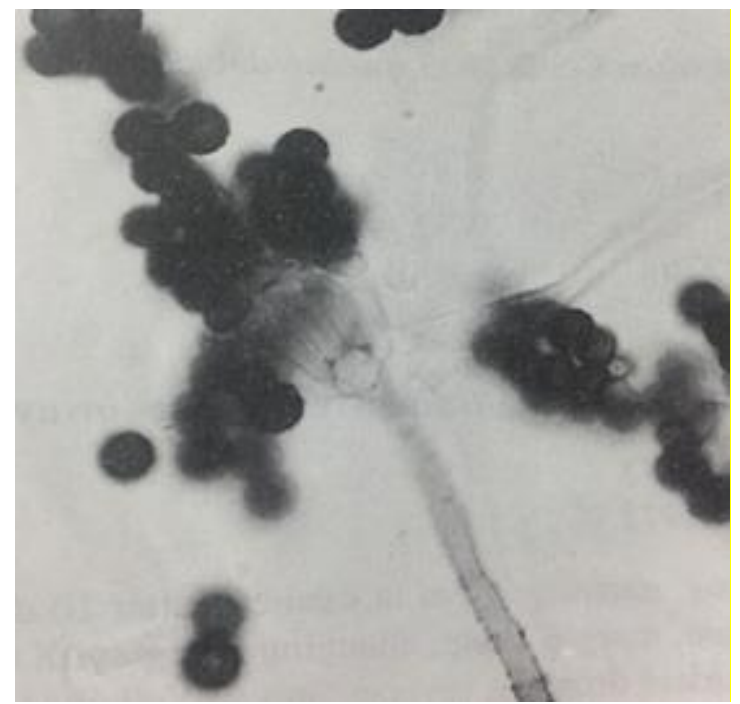

Figure (2). Memnoniella spp., different species, Photo was taken by Dr. Moubasher AH. [16].

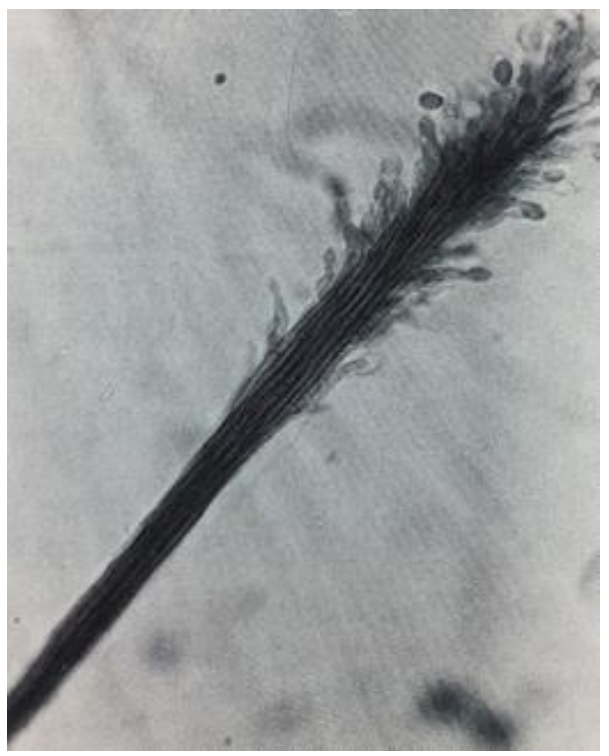

Figure (3). Doratomyces spp., different species, Photo was taken by Dr. Moubasher AH. [16]. 


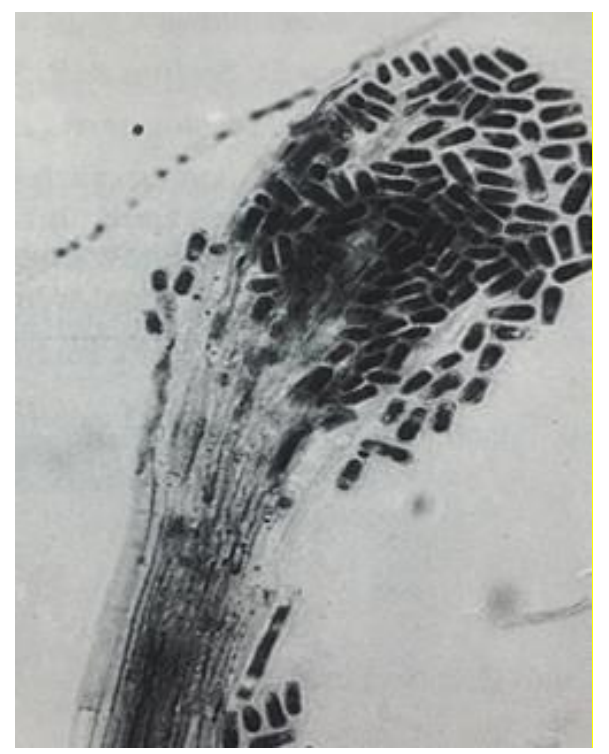

Figure (4). Graphium spp., different species, Photo was taken by Dr. Moubasher AH. [16].

\section{Stachybotrys secondary metabolites}

The genus Stachybotrys produces a broad diversity of secondary metabolites, including macrocyclic trichothecenes, atranones, and phenylspirodrimanes. Although the class of the phenylspirodrimanes is the major one and consists of a multitude of metabolites bearing various structural modifications, few investigations have been carried out. This review highlighted the secondary metabolites produced by different Stachybotrys species [17]. Micro-scale extracts from 5 different Stachybotrys strains, which were cultured on different media, spontaneous dialdehyde/lactone isomerization was observed for some of the isolated secondary metabolites, and novel stachybotrychromenes were quantitatively investigated. The metabolite profiles of Stachybotrys species are considerably influenced by different factors (Time of growth and substrates) and different species [17].

The genus Stachybotrys can be found in nature as well as in the indoor environment, and cellulose-rich substrates containing high moisture levels are generally required for Stachybotrys growth [18]. Fungal growth in water-damaged buildings poses serious human health risks and can lead to allergic and respiratory issues [19]. Stachybotrys chartarum has been the subject of considerable attention due to transitory associations with idiopathic pulmonary loss in infants [20] and disease symptoms called sick building syndrome [21]. There are still controversial discussions concerning the role of Stachybotrys within these reported cases, concluding that there is inadequate evidence that exposure to mycotoxins is causally related to the adverse human health effects [22]. Nevertheless, Stachybotrys produces a broad variety of toxic secondary metabolites, which are of relevance in the indoor environment concerning human health $[23,24]$. The most common species among this genus are Stachybotrys elegans and Stachybotrys chartarum, which were also found in the indoor environment [14]. Stachybotrys chartarum, is a toxic fungi, and common found in indoor air and causing mycotoxicosis, chronic fatigue, allergic diseases and other health problems

Searching for novel and bioactive molecules of microbial origin for drug development, Stachybotrys and Memnoniella fungi generally have been found to be a rich source of novel and bioactive secondary metabolites of great importance. Results of phylogenetic analyses were in agreement that the Memnoniella is paraphyletic to Stachybotrys. Interestingly, most Memnoniella spp. were found to produce the similar chemical substances. Up until now, almost 200 secondary metabolites belonging to diverse structural types of trichothecene, triprenyl phenol, diterpenoid, isochroman, polyketide, cochlioquinone and cyclic peptide have been discovered. Most of these fungal metabolites were reported to possess several interesting biological activities, such as disruption of the complement system, inhibition of TNF- $\alpha$ release, endothelin receptor antagonism, anti-influenza A virus, antimalarial, inhibition of avian myeloblastosis virus protease, cholesterol esterase, tyrosine kinase, farnesyl-protein transferase, squalene synthase and human heart chymase as well as stimulation of plasminogen, fibrinolysis, thrombolysis [25].

\section{Memnoniella secondary metabolites}

Memnoniella, according to phylogenetic analyses, is paraphyletic to Stachybotrys, and both produce similar secondary metabolites. Many secondary metabolites belonging to various chemical classes including trichothecene, triprenyl phenol, diterpenoid, isochroman, polyketide, cochlioquinone and cyclic peptide have been reported to be produced by this fungus [25]. Memnoniella produces many trichothecenes which are sesquiterpenoid mycotoxins such as trichodermin, trichodermol and phenylspirodrimanes [26]. On the other hand, Phenylspirodrimanes are signature secondary metabolites of both Memnoniella and Stachybotrys [27]. This generous production of secondary metabolites is accompanied with promising different biological activities including antiviral, antimalarial, TNF- $\alpha$ release inhibition, endothelin receptor antagonism. Also as potent inhibitor of tyrosine kinase, cholesterol esterase, farnesylprotein transferase, human heart chymase squalene synthase, and stimulator of plasminogen, fibrinolysis, thrombolysis [25].

\section{Doratomyces secondary metabolites}

Doratomyces microsporus is a famous producer of keratinase [28]. This species is a non-toxins producer, and it has a promising capability to biodegrade human stratum corneum [29]. Doratomyces has a considerable role in biodegradation of biphenyls compounds, especially species Doratomyces nanus, Doratomyces purpureofuscus, Doratomyces verrucisporus $[30,31]$. On the other hand, Doratomyces was reported as statins producer [32, 33]. Adding valproic acid to Doratomyces microsporus culture induced production of seven antimicrobial compounds that showed activity against Staphylococcus aureus and several methicillin-resistance $S$. aureus (MRSA) [34].

\section{Graphium secondary metabolites}

Marine-derived fungi are well known as rich sources of bioactive natural products. Indole alkaloids, isolated from a variety of marine-derived fungi 
especially Graphium genus, have attracted considerable attention for their diverse, challenging structural complexity and promising bioactivities, and consequently, indole alkaloids have potential to be pharmaceutical lead compounds [35]. Graphiumins A-J, bearing structurally rare DKPs with a phenylalanine-derived indolin substructure, were isolated from the culture broth of the marine-derived fungus Graphium sp. OPMF00224. Graphiumins A-J Compounds inhibited yellow pigment production by methicillin-resistant Staphylococcus aureus [36].

Fungi show remarkable potency to bioremediate hydrocarbons with complex structure and long-chain length such as Neosartorya, Graphium, Aspergillus, Talaromyces, Cephalosporium, Penicillium and others these genera were isolated from soil polluted with petroleum and also found to be the effective organisms for bioremediation of hydrocarbons in crude oil [37]. Kaur et al., [38], reported that Graphium spp. has the ability to biodegrade methyl-tert-butyl ether

\section{Conclusion}

Fungi are a noble and consistent source of unique natural products with a high level of biodiversity and also yield several compounds having different pharmaceutical activities, which is currently attracting scientific researches. Every study conducted on Stachybotrys, Memnoniella, Doratomyces and Graphium resulted in discovery of new metabolites or pointing to a possible application, which made these genera potential source of pharmaceuticals and attracted attention for further investigations of their important bioactivities properties. Stachybotrys, Memnoniella, Doratomyces and Graphium are known for their capability of producing various biologically active compounds with medical applications as antimicrobial, anticancer, anti-influenza A virus, antimalarial and others.

\section{References}

1. Alberti F, Foster GD, Bailey AM. (2017). Natural products from filamentous fungi and production by heterologous expression. Applied microbiology and biotechnology, 101(2): 493-500.

2. Verma VC, Kharwar RN, Strobel GA. (2009). Chemical and functional diversity of natural products from plant associated endophytic fungi. Natural product communications, 4(11): $1934578 X 0900401114$.

3. Schueffler A, Anke T. (2014). Fungal natural products in research and development. Natural product reports, 31(10): 1425-1448.

4. Elkhateeb WA, Daba GM. (2018) Where to Find? A Report for Some Terrestrial Fungal Isolates, and Selected Applications Using Fungal Secondary Metabolites. Biomed Journal Science \&Technology Research; 4(4): 1-4.

5. Elkhateeb WA, Daba GM. (2019) The amazing potential of fungi in human life. ARC J. Pharma. Sci. AJPS, 5(3): 12-16.

6. Elkhateeb WA, Daba GM. (2018) Epicoccum species as potent factories for the production of compounds of industrial, medical, and biological control applications. Biomedical Journal of Scientific and Technical Research, 14: 10616-10620.

7. Elkhateeb WA, Daba GM. (2019) Myrothecium as promising model for biotechnological applications, potentials and challenges. J. Sci. Res, 16: 12126-12131.

8. Daba GM, Mostafa FA, Elkhateeb WA. (2021) The ancient koji mold (Aspergillus oryzae) as a modern biotechnological tool. Bioresources and Bioprocessing, 8(1): 1-17.

9. Daba GM, Elkhateeb WA, Thomas PW. (2018) This era of biotechnological tools: an insight into endophytic mycobiota. Egyptian Pharmaceu J, 17(3): 121-128.

10. Elkhateeb WA, EL-Ghwas DE, AL Kolaibe AG, Akram M, Daba GM (2021) Yeast the Present and Future Cell Facture. Journal of Mycology \& Mycological Sciences, 4(2): 1-5.
11. Elkhateeb WA, Elnahas MO, Daba GM, Zohri AN. (2021) Biotechnology and Environmental applications of Trichoderma spp Research Journal of Pharmacognosy and Phytochemistry, 13(3): 149-157.

12. Elkhateeb WA, Kolaibe AG, Daba GM. (2021) Cochliobolus, Drechslera, Bipolaris, Curvularia different nomenclature for one potent fungus. Journal of Pharmaceutics and Pharmacology Research, 4(1): 1-6.

13. Elkhateeb WA, Kolaibe AG, Elnahas MO, Daba GM. (2021) Highlights on Chaetomium morphology, secondary metabolites and biological activates. Journal of Pharmaceutics and Pharmacology Research, 4(1): 1-5.

14. Elkhateeb WA. (2005) Some mycological, phytopathological and physiological studies on mycobiota of selected newly reclaimed soils in Assiut Governorate, Egypt (M. Sc. Thesis, Faculty of Science, Assuit University, Egypt. p 238.

15. Elkhateeb WA, Zohri AA, Mazen M, Hashem M, Daba GM. (2016) Investigation of diversity of endophytic, phylloplane and phyllosphere mycobiota isolated from different cultivated plants in new reclaimed soil, Upper Egypt with potential biological applications, Inter J MediPharm Res, 2(1): 23-31.

16. Moubasher AH. (1993). Soil fungi in Qatar and other Arab countries. Doha, Qatar: The Scientific And Applied Research Centre University of Qatar; 1993. 566. 22.

17. Jagels A, Lindemann V, Ulrich S, Gottschalk C, Cramer B, Hübner F, Humpf HU. (2019). Exploring secondary metabolite profiles of Stachybotrys spp. by LC-MS/MS. Toxins, 11(3): 133.

18. Andersen B, Dosen I, Lewinska AM, Nielsen KF. (2017). Precontamination of new gypsum wallboard with potentially harmful fungal species. Indoor Air. 27: 6-12.

19. Mendell M, Mirer A, Cheung K, Tong M, Douwes J. (2011) Respiratory and allergic health effects of dampness, mold, and dampness-related agents: A review of the epidemiologic evidence. Environ. Health Perspect. 119: 748-756.

20. Dearborn DG, Yike I, Sorenson WG, Miller MJ, Etzel RA. (1999). Overview of investigations into pulmonary hemorrhage among infants in Cleveland, Ohio. Environ. Health Perspect. 107: 495499.

21. Hossain MA, Ahmed MS, Ghannoum MA. (2004). Attributes of Stachybotrys chartarum and its association with human disease. J. Allergy Clin. Immunol. 113: 200-208.

22. Page EH, Trout DB. (2001). The Role of Stachybotrys Mycotoxins in Building-Related Illness. Am. Ind. Hyg. Assoc. J. 62: 644-648.

23. Miller J.D., McMullin D.R. (2014). Fungal secondary metabolites as harmful indoor air contaminants: 10 years on. Appl. Microbiol. Biotechnol., 98: 9953-9966.

24. Fromme H, Gareis M, Völkel W, Gottschalk C. (2016). Overall internal exposure to mycotoxins and their occurrence in occupational and residential settings-An overview. Int. J. Hyg. Environ. Health. 219: 143-165.

25. Wang A, Xu Y, Gao Y, Huang Q, Luo X, An H, Dong J. (2015). Chemical and bioactive diversities of the genera Stachybotrys and Memnoniella secondary metabolites. Phytochemistry reviews, 14(4): 623-655.

26. Jarvis BB, Sorenson WG, Hintikka EL, Nikulin M, Zhou Y, Jiang J. (1998). Study of toxin production by isolates of Stachybotrys chartarum and Memnoniella echinata isolated during a study of pulmonary hemosiderosis in infants. Appl Environ Microbiol 64:3620-3625.

27. Li Y, Wu CM, Liu D, Proksch P, Guo P, Lin WH. (2014). Chartarlactams A-P, phenylspirodrimanes from the spongeassociated fungus Stachybotrys chartarum with antihyperlipidemic activities. J Nat Prod 77:138-147. 
28. Gradišar HK, Kern S, Friedrich J. (2000). Keratinase of Doratomyces microsporus. Applied Microbiology and Biotechnology, 53(2): 196-200.

29. Srivastava B, Khatri M, Singh G, Arya SK. (2020). Microbial keratinases: an overview of biochemical characterization and its eco-friendly approach for industrial applications. Journal of Cleaner Production, 252, p.119847.

30. Mouhamadou B, Faure M, Sage L, Marçais J, Souard F, Geremia RA. (2013). Potential of autochthonous fungal strains isolated from contaminated soils for degradation of polychlorinated biphenyls. Fungal biology, 117(4): 268-274.

31. Yadav N, Yadav AN. (2019). Biodegradation of biphenyl compounds by soil microbiomes. Biodivers Int J, 3: 37-40.

32. Alarcon J, Aguila S, Arancibia-Avila P, Fuentes O, ZamoranoPonce E, Hernández M. (2003). Production and purification of statins from Pleurotus ostreatus (Basidiomycetes) strains. Zeitschrift für Naturforschung C, 58(1-2): 62-64.

33. Demain AL. (2014). Valuable Secondary Metabolites from Fungi. In: Martín JF., García-Estrada C., Zeilinger S. (eds) Biosynthesis and Molecular Genetics of Fungal Secondary Metabolites. Fungal Biology. Springer, New York, NY.
34. Nekati LP. (2021). Induction of secondary metabolite production in endophytic fungi isolated from Albizia adianthifolia using multiple small compounds involved in fungal chromatin remodeling (Doctoral dissertation).

35. Meng ZH, Sun TT, Zhao GZ, Yue YF, Chang QH, Zhu HJ, Cao F. (2021). Marine-derived fungi as a source of bioactive indole alkaloids with diversified structures. Marine Life Science \& Technology, 3(1): 44-61.

36. Fukuda T, Shinkai M, Sasaki E, Nagai K, Kurihara Y, Kanamoto A, Tomoda H (2015). Graphiumins, new thiodiketopiperazines from the marine-derived fungus Graphium sp. OPMF00224. $J$ Antibiot. 68: 620-629.

37. Das N, Chandran P. (2011). Microbial degradation of petroleum hydrocarbon contaminants: an overview. Biotechnol Res Int. 113

38. Kaur G, Kaur D, Gupta, S. (2021). The Role of Microorganisms in Remediation of Environmental Contaminants. In Environmental Pollution and Remediation, 421-450. Springer, Singapore.
This work is licensed under Creative Commons Attribution 4.0 License
To Submit Your Article Click Here: Submit Manuscript

DOI: $10.31579 / 2766-2314 / 066$
Ready to submit your research? Choose Auctores and benefit from:

$>$ fast, convenient online submission

$>$ rigorous peer review by experienced research in your field

$>$ rapid publication on acceptance

$>$ authors retain copyrights

$>$ unique DOI for all articles

$>$ immediate, unrestricted online access

At Auctores, research is always in progress.

Learn more https://auctoresonline.org/journals/biotechnology-andbioprocessing- 